\title{
Psychiatric training and research in Ireland, the trainee's perspective
}

\author{
Nnamdi Nkire, Osamede Edokpolo
}

\author{
Ir J Psych Med 2011; 28(1): 3-5
}

Research recognises no boundaries of class, culture or status. It is critical and iconoclastic, as indeed should be the psychiatric trainee.

- Chris Freeman \& Peter Tyrer. ${ }^{1}$

Psychiatric training in Ireland is comprised of a period of Basic Specialist Training (BST) succeeded by a Higher Specialist Training (HST) programme. The BST in Ireland has been well organised since the late 1970s. ${ }^{2}$ This was initially conducted by the Irish Psychiatric Training Committee (IPTC) in liaison with the Royal College of Psychiatrists but since January 1, 2009 it has been brought under the umbrella of the newly formed College of Psychiatry of Ireland. The BST usually culminates in acquisition of the MRCPsych on passing the membership examination of the Royal College of Psychiatrists.

A significant number of psychiatric trainees proceed to post-membership positions in subspecialties, where available, while others engage in research as research fellows/ assistants or lecturing posts before proceeding to the HST. This period serves as a form of a gap year(s) where trainees acquire the skills necessary to conduct research, teach and manage people and resources. In addition, one such year may be approved retrospectively towards higher training when a place is secured on the HST.

Following this period, many trainees apply for places on HST scheme. However application for places usually exceeds available vacancies. The HST may take a further three to four years to complete. During the HST a trainee is addressed as a senior registrar and has more clinical and managerial responsibilities. On completion of HST, a trainee acquires a certificate of satisfactory completion of specialist training (CSCST). ${ }^{3}$ This certificate enables the specialist to practise psychiatry independently and confers eligibility for registration on the Register of Specialists of the Irish Medical Council. Specialist registration is necessary for appointment as a substantive consultant psychiatrist in Ireland.

In other jurisdictions like the UK, training for psychiatrists appears to be in a state of flux. It moved from the system of training described above to a run-through system where a trainee progressed through year one (ST1) without breaks, to the end point on completion of six years at ST6, following which there was an award of a certificate of completion of specialist training. This system is currently being reviewed with moves to change to a system that resembles the previously available one in some shape or form. In contrast in the

*Nnamdi Nkire, MRCPsych, Clinical Research Fellow/Registrar, Cavan-Monaghan First Episode Psychosis Study, St. Davnet's Hospital, Monaghan, Osamede Edokpolo, Registrar, HSE Addiction Services, Tallaght, Dublin 24, Ireland.

${ }^{*}$ Correspondence

SUBMITTED: AUGUST 18, 2009. ACCEPTED: MARCH 30, 2010.
US, trainees (residents) undergo four years of basic psychiatric training (PGY1 to PGY4) following completion of which they become an 'Attending' and board certified practitioners on passing board certification examinations. They may if they choose to, go on to complete fellowships in different subspecialties. This appears straightforward, however recent trends indicate declining numbers of US psychiatric residents and downsizing of training programmes. ${ }^{4}$ Anecdotal evidence suggests similar trends in Ireland such that in Ireland as in the US many training positions are filled by foreign-trained medical graduates.

The synopsis of psychiatric training in Ireland elaborated above appears well structured, but like all systems, there have been snags at various points in the system. Psychiatry has been reported to be the most rapidly changing and developing specialty of all the medical specialties in Ireland. ${ }^{2}$ Indeed some authors have echoed that psychiatric training in Ireland is traversing a crucial and challenging time. ${ }^{5}$ These changes have accrued from changes in medical education, an increase in the number of trainees in recent times, limited vacancies on the HST scheme and restructuring of the health system.

Transitions

Places on HST are obtained by competitive interview. The number of positions on the scheme has doubled over the last decade to approximately 54 posts as at $2005^{6}$ and 101 as at $2009 .{ }^{3}$ However, the number of basic psychiatry trainees has also increased during this period and as at 2009 stood at 384. ${ }^{3}$ As such, competition for places on the HST remains quite fierce, with the numbers of trainees applying for places outstripping the number of places on the HST by ratios as high as $4: 1$. This bottleneck was quite apparent in the last round of interviews for senior registrar's positions (2009); there were approximately 70 applicants for about 15 vacancies. $^{3}$

The CPI has continued to respond to this competition by strictly enforcing the pre-requisite criteria for admission into HST, including possession of pre-requisite management, teaching, psychotherapy, post-membership and research experience, in order to be shortlisted for interview. The enforcement of these criteria by the training committee of the $\mathrm{CPI}$ is commendable because it leads to maintenance of, and/or increases standards. This runs with the notion that the cream will rise to the top.

In Ireland, the disparity in vacancies between HST and the basic training schemes, coupled with a limited availability of post-membership positions in research and lecturing, has lead to even further pressure on psychiatric trainees who pass the MRCPsych examinations. Anecdotally, this resulted in a situation where trainees were reluctant to sit the final part of the exam in previous years. This appears to have improved in recent years, with the imposition and enforcement of time 
limits on basic training schemes due to an increase in availability of doctors seeking psychiatry as a career option.

Post acquisition of MRCPsych, and in the face of a lack of availability of adequate numbers of post-membership academic positions, many trainees have gone on to work as locum consultants in Ireland or the UK, while others have emigrated to Australia, New Zealand or Canada on foot of more promising career options. This has resulted in a brain drain and the loss of a pool of trainees on whom significant resources were spent by way of the training grants.

It must be noted, however, that at the time of acquiring the MRCPsych, a significant number of basic trainees have little in the way of research, management and/or teaching experience. A significant amount of time and effort has been concentrated on acquiring the MRCPsych, which is a badge of honour within the rank of trainees. Moreover, many are unaware of the other requirements of basic training or the criteria for admission into HST. At this point the gulf between the expectations of the training committee of the CPI regarding its training criteria and the knowledge of and/or attitude of trainees towards these expectations becomes apparent. Indeed, it highlights the failure on the part of trainees to read the trainee handbook and take responsibility for achieving substantial parts of their training requirement. On the other hand, it may reflect a failure of adequate supervision and monitoring of early training. However, it must be noted that the $\mathrm{CPI}$ are currently preparing a new training handbook and developing strategies to ensure better supervision.

As the seeds of pragmatic interest in management, research and psychotherapy are not sown early, some trainees view the two or three years post-membership spent on gaining the necessary experience in these areas as just time to "tick the boxes". This can become a cumbersome and laborious experience, rather than a joyous one inspired by genuine interest. Trainees and research

Research is a necessary part of medical training. There are several aspects to clinical research, including the practical aspect of carrying out research, presentation and reporting of clinical cases, literature reviews, the evaluation of published research work and interpretation of data and its application to clinical practice. The CPI has recommended that every trainee should have some experience of supervised research. In addition, it advocates that each training scheme should have a research tutor to advise trainees on the suitability of projects for their level of experience.

The focus on research in recent time has become even more acute. This is because of the recent drive towards evidence-based medicine. Evidence-based medicine (EBM) is founded on the philosophical traditions of mid-19th century Paris and earlier times, but the fad has been prominent since the latter part of the last century. Evidence-based medicine seeks to integrate best research evidence with clinical expertise and patient values in order to ensure the best outcome for patients. ${ }^{7}$

Psychiatry is not insulated from this drive to achieve better outcomes through EBM. However as noted by Fogel in a recent review article there appears to be pressure on clinical services in many academic psychiatry departments with subsequent neglect of research and insufficient number of psychiatric researchers. ${ }^{8}$ Other problems identified in this article as affecting psychiatric research include lack of structure to the research training experience, lack of time, difficulty choosing a topic which would not conflict with the demands of clinical work, not having a designated advisor for research and obtaining a large enough sample. ${ }^{8}$

There is a process of reformation of educational strategies and curriculum for trainee psychiatrist by the CPI. For the trainee it is not just a question of acquiring the necessary clinical skill set to ensure good patient care, it also involves engagement in research and examining aspects of one's work by way of audits, so as to ensure compliance with international standards of care. In addition, it involves sieving through a myriad of published papers with an eagle eye and a keen mind, to decipher what is a significant result and what is not.

Much of this skill-set is inadequately harnessed in undergraduate training so postgraduate training should seek to address the shortfall. It is commendable that the training committee of the CPI has made this one of the core planks for acceptance into the HST scheme. Many trainees consider research as one of the most important pre-requisites for getting a place on the HST. ${ }^{9}$ At the post-membership level, there are more opportunities for research. These are concentrated in big centres under the supervision of eminent clinical and academic researchers and are usually designated as post-membership research positions with some having clinical responsibilities as well as an opportunity to obtain an MD. Some of these researches are on psychosis, genetics, depression, etc and an exhaustive list can be found in the trainee's handbook. ${ }^{2}$ Because of the requirement of having engaged in a research project before short-listing for the HST, many higher specialist trainees would have been involved in conducting, presented or published a research piece. Furthermore, the Higher Specialist Trainee Handbook (1998) has highlighted the importance of research by echoing the sentiments of the previous Higher Specialist Training Committee which required higher specialist trainees to have two sessions per week devoted to planning, conducting and communicating the outcome of research projects. Ramachandani et al have highlighted some problems facing research at this level including poorly structured training experience with many trainees failing to achieve a publication. ${ }^{10}$

At the BST stage, the expectation to engage with research appears to have posed a seemingly cumbersome burden on these trainees who appear ill-prepared for it. Usually, new trainees spend the first year of their journey into psychiatric training grappling with basic concepts of psychiatric diagnosis, history-taking and patient care. They attend weekly academic/journal club meetings and in some instances are expected to present journal articles. Anecdotal evidence shows that most trainees view these sessions with trepidation, especially when they are due to present cases. This stems from their lack of preparedness and knowledge of the process of critical appraisal. Many journal clubs end with the trainee having to read through journals like newscasters, thus fostering some scepticism of the process. This can have the effect of turning seemingly fertile young minds off psychiatric research.

The theoretical puzzle regarding research usually falls into place in the paper 2 and 3 of the MRCPsych examination, when trainees are adequately exposed to the process by the curriculum. However, by this time most trainees are preoccupied with passing the exams and acquiring membership of the Royal College with little time for the practical aspects of research. The exams themselves are hard enough and it 
is hardly surprising that many registrars spend a large part of their training grappling with the membership exams to the detriment of other aspects of training, including practical things like audits, and critical appraisal. Timing is important in any process. It thus behoves all psychiatric training schemes in the country to address this shortcoming by factoring research into their academic programmes early enough, before the seeds of fear and cynicism are sown.

Mentoring is an essential ingredient in striving to achieve better quality psychiatric research and excellence in training. ${ }^{11}$ Medical training is a process of apprenticeship, during which trainees model themselves on the senior colleagues who have impacted upon them. In a study in the UK of 69 psychiatry trainees cited by Fogel in his review article, only $9 \%$ were strongly encouraged by their supervisors to participate in research projects, while 35\% received no such encouragements at all, and of trainees in a busy post 56\% reported that their supervisors ignored or discouraged research participation. ${ }^{8}$ Many trainees have little inkling of how to proceed with the research process. As such, proper guidance and supervision is necessary. This is why it is important that every training scheme has a research supervisor/tutor to lead and mentor research activity of its trainees. The research mentor should not only provide research direction but should be generous with authorship, assist with presentations at conferences and help the trainee interact with other members of the research community. ${ }^{8}$

One of the authors of this paper was first introduced to research and how to write a paper by a previous consultant, who not only chose a research topic but actively encouraged the said registrar to set a time limit for completion of the project in order to present same at regular journal meetings. This supervision was achieved through regular monthly research meetings on a set day of the week. This was an invaluable experience and lead to the first published work of the author in a peer-reviewed journal and has acted as a compass and building block for future research projects. The process of mentoring will kindle and nurture the spark for research and evidence-based medicine much earlier in the training cycle.

There needs to be adequate enforcement of protected supervision hours for trainees. These sessions could serve as dedicated time to examine research topics and clinical papers and how to evaluate such papers or implement and monitor research projects.

Furthermore, psychiatric training schemes could be modelled on some form of incentivisation for research; for example in the US, some training programmes have successfully integrated active research and clinical work in early postgraduate years through rewards. ${ }^{12}$ This is achievable in Ireland through yearly sponsorship of research awards and prizes, such as is already present in some training schemes in Ireland. It is worth noting that the RCSI/Beaumont hospital and the Royal Academy of Medicine of Ireland (RAMI) have taken the lead in this respect, however, the process needs more publicity.

Training schemes could and should have joint bulletins where trainees' researches are published. This will have the added incentive of teaching trainees how to get published in peer-reviewed journals and hence improve their writing skills. These bulletins and their published material could serve as a useful source of data and evidence base for different aspects of psychiatry in Ireland and fertile ground for ideas for future large-scale research. This would help alleviate the apparent paucity of psychiatric research in Ireland. Alternatively trainees could be encouraged to publish in existing journals by dedicating a section of such journals to research by basic psychiatry trainees, bearing in mind that trainees are competing for publishing in these journals with more experienced researchers and senior colleagues.

The CPI in developing its curricula for psychiatric training should consider making research and critical appraisal as mandatory first-year training requirements. In addition, it should aim to develop and enforce the use of log books or a portfolio system, to enable better documentation of training and research.

It is vital that trainees at the beginning of each six month's posting have set educational objectives including a piece of audit/research, as is currently the case in some schemes for example at the Central Mental Hospital, Dundrum. These objectives should be reassessed at the fourth month and sixth month of each posting and adequately graded. At the end of each year, trainees can then be placed and awarded prizes on the basis of their grades.

\section{Conclusion}

Psychiatry as a specialty in Ireland is undergoing changes and the training of psychiatrists is not exempt from these changes. The quality of psychiatry trainees continues to improve, with an emphasis on the core principles of clinical practise in addition to gaining necessary experience in management and research. The focus on research is important as psychiatry continues to expose itself to more evidence-based practice. It is necessary for psychiatry trainees to be well versed in psychiatric research methodology. As such an enabling environment and process must be established by the $\mathrm{CPI}$ and its training arm to ensure that all trainee psychiatrists acquire this basic skill. However, it must be stated that research as part of the training curricula should not be overemphasised to the detriment of other core skills necessary to be a good psychiatrist.

Acknowledgements: We are grateful to Drs Ena Lavelle and Annette Kavanagh for their inspiration in the field of research; and to Prof John Waddington for his invaluable advice in the writing of this article.

\section{Declaration of Interest: None}

References

1. Freeman C, Tyrer P. Research methods in psychiatry, Gaskell. Royal College of Psychiatrists 2006: 3.

2. Halpin CM. Psychiatry training in the Republic of Ireland, a resource book for trainees, Irish College of Psychiatrists 2005: 4.

3. www.irishpsychiatry.com/career.htm

4. Rao NR. Recent trends in psychiatry residency workforce with special reference to international medical graduates. Academic Psychiatry 2003; 27: 269-276.

5. Guerandel A, MacSuibhne S, Malone K. Best evidence medical education and psychiatry in Ireland: a three step frame work for change. Irish Journal of Psychological Medicine 2008; 25(4): 120-122.

6. Psychiatry training in the Republic of Ireland, a resource book for trainees, Irish College of Psychiatrists 2005: 10.

7. www.cebm.utoronto.ca/intro/whatis.htm.

8. Fogel J. Research as part of the career of a psychiatrist entering clinical practice. Psychiatric Bulletin 2009; 33: 269-272.

9. Quinn J, Meagher D. Psychiatric trainees' research experiences and activities in the eastern region of Ireland. Psychiatric Bulletin 1997; 21: 367-368.

10. Ramchandani P, Corby C, Guest L, Cole-King A. The place and purpose of research training for specialist registrars: a view from the Collegiate Trainees' Committee (CTC) of the Royal College of Psychiatrists. Ir J Psychol Med 2001; 18(1): 27-29.

11. Kunik ME, Hudson S, Schubert B, Nasralla H, Kirchner JE, Sullivan G. Growing Our Own: A regional approach to encourage psychiatric residents to enter research. Academic Psychiatry 2008; 32: 236-240.

12. Anonymous. House staff team research in the ambulatory setting: it can be done. 